\title{
Effect of tetracyclines on pulpal and periodontal healing after tooth replantation: a systematic review of human and animal studies
}

Mingmei Meng ${ }^{1,2}$, Yandi Chen ${ }^{1,2}$, Huidi Ren ${ }^{1,2}$, Qiong Zhang ${ }^{1,2}$, Song Chen ${ }^{1,2}$, Xuedong Zhou ${ }^{1,3^{*}}$ and Jing Zou ${ }^{1,2^{*}}$

\begin{abstract}
Background: Pulpal and periodontal healing are two main concerns of delayed replantation of avulsed teeth. The objective of this review was to evaluate the effectiveness of topical and systemic application of tetracyclines on pulpal and periodontal healing after tooth replantation.

Methods: A comprehensive electronic search was conducted in six databases. This systematic review was carried out according to Cochrane Handbook and the Preferred Reporting Items for Systematic Reviews and Meta-Analyses (PRISMA) statement.

Results: After exclusion of 246 irrelevant papers, 14 animal studies and one human study were included in this review. The human study showed that avulsed permanent teeth treated with doxycycline did not show a better clinical outcome for pulp and periodontal healing compared with treatment with normal saline. As for animal studies, significant more pulpal healing was observed in immature teeth treated with topical doxycycline in two researches, while another one study showed that there is no difference between teeth treated with normal saline and teeth treated with doxycycline. Systemic doxycycline exerted no significant effect on pulpal revascularization illustrated by one research. Only one out of four articles illustrated the positive effect of systemic tetracyclines on periodontal healing. One paper reported that intracanal application of demeclocycline promoted favorable periodontal healing. Two articles showed topical doxycycline contributed to favorable periodontal healing, while five studies showed no significant effect of topical tetracyclines on periodontal healing.

Conclusions: As a result of data heterogeneity and limitations of the studies, the effect of topical or systemic application of tetracyclines on pulpal and periodontal healing is inconclusive. More studies are required to get more clinically significant conclusions.
\end{abstract}

Keywords: Tetracyclines, Tooth replantation, Pulpal healing, Periodontal healing

*Correspondence: zhouxd@scu.edu.cn; zoujing1970@126.com

1 State Key Laboratory of Oral Diseases and National Clinical Research Center for Oral Diseases, West China Hospital of Stomatology, Sichuan University, Sichuan, China

Full list of author information is available at the end of the article

\section{Background}

Dental trauma, occurring frequently in patients between 7 and 15 years of age, affects the maxillary central incisors most [1]. Avulsion, the complete luxation of a tooth from its alveolar fossa, may cause a variety of complications related to pulp and periodontal tissues. The

(c) The Author(s) 2021. This article is licensed under a Creative Commons Attribution 4.0 International License, which permits use, sharing, adaptation, distribution and reproduction in any medium or format, as long as you give appropriate credit to the original author(s) and the source, provide a link to the Creative Commons licence, and indicate if changes were made. The images or other third party material in this article are included in the article's Creative Commons licence, unless indicated otherwise in a credit line to the material. If material is not included in the article's Creative Commons licence and your intended use is not permitted by statutory regulation or exceeds the permitted use, you will need to obtain permission directly from the copyright holder. To view a copy of this licence, visit http://creativecommons.org/licenses/by/4.0/. The Creative Commons Public Domain Dedication waiver (http://creativecommons.org/publicdomain/zero/1.0/) applies to the data made available in this article, unless otherwise stated in a credit line to the data. 
development of pulp necrosis, pulp canal obliteration, arrested or incomplete root formation, external resorption, inflammatory resorption, permanent replacement resorption, transient replacement resorption, internal root resorption, loss of marginal attachment and tooth loss are possible healing complications secondary to tooth avulsion [2,3].

Factors related to pulpal healing, root growth and periodontal healing after tooth avulsion have been widely studied. Stage of root development, the distance from the apical foramen to the pulp horns, the time and condition of extra-alveolar storage, and atopic feature are issues frequently considered [4-11]. It is widely accepted that suitable management for first-aid measures and immediate replantation of avulsed tooth is the best for prognosis. Delayed replantation and unphysiological storage is followed by low survival [12].

Attempts have been made to facilitate greater pulp and periodontal healing, and greater lifetime of the replanted teeth. Thymosin alpha 1, enamel matrix derivative, fibroblast growth factor, triamcinolone, bisphosphonates dexamethasone, 3Mix (the mixture of ciprofloxacin, metronidazole, and minocycline), Cathepsin $\mathrm{K}$ inhibitor and fluoride are medicines tried in different models to provide short-term and long-term benefits in the replantation of avulsed teeth [13-22]. They might exert their beneficial effect on replanted teeth by inhibiting the activity of osteoclasts, controlling the inflammation through decreased $\mathrm{C}$-reactive protein, or favoring the formation of new periodontal ligament.

Minocycline, one component of $3 \mathrm{Mix}$, has been reported to suppress osteoclast differentiation and accelerate odontoblast like cell differentiation in intentionally delayed tooth replantation in mice, improving pulpal healing after tooth injuries [20]. Other tetracyclines have also been applied in avulsed teeth topically or systemically in the purpose of promoting pulp revascularization and periodontal healing [21, 23-37]. Tetracyclines, a group of broad-spectrum antibiotics, either natural or semi-synthetic, exert their antimicrobial activity by inhibiting protein synthesis. They have been widely used in stomatology, such as regenerative endodontics, white spongy naevus, periodontitis, peri-implantitis, herpes labialis, recurrent aphthous stomatitis [38-43]. The mechanism of action in these conditions is not totally understood, but its efficacious antibiotic properties, the inhibitory effect of collagenase and osteoclastic activity, and its enhancement of fibroblastic attachment to facilitate periodontal regeneration might contribute to these clinical effects [44-48].

An animal study suggested no beneficial effect of systemic use of doxycycline in facilitating complete pulp revascularization and inhibiting micro-organisms in the pulp lumen [23]. Another research had different results, revealing that the topical application of doxycycline could increase the frequency of complete pulp revascularization and decrease the frequency of micro-organisms in the pulpal lumen, ankylosis and inflammatory root resorption [24]. Therefore, a systematic review of available knowledge is in need to comprehensively evaluate the effect of tetracyclines on pulp revascularization and periodontal healing in replanted teeth, with the intent of getting instructive information for clinical practice.

\section{Material and methods}

This systematic review was conducted in accordance with Cochrane Handbook for Systematic Review of Interventions and Preferred Reporting Items for Systematic Reviews and Meta-Analyses (PRISMA). Two reviewers (MM and $\mathrm{YC})$ conducted the search and the work of extracting data, and assessed the risk of bias and eligibilities of the retrieved articles independently and in duplicate. Any disagreement was resolved by discussing with a third reviewer (JZ).

\section{Search strategy}

An extensive electronic search was made through PubMed, Embase (via Ovid), Web of Science, Cochrane Central Register of Controlled Trials (CENTRAL), and ProQuest research Library (PRL). The electronic search was conducted in different databases from their date of inception up to April 2021, with no language limitation. The following search terms were used in Pubmed: ("tetracyclines" [MeSH Terms] OR "tetracyclines" [All Fields] OR "chlortetracycline" [All Fields] OR "demeclocycline" [All Fields] OR "doxycycline" [All Fields] OR "lymecycline" [All Fields] OR "methacycline" [All Fields] OR "minocycline" [All Fields] OR "oxytetracycline" [All Fields] OR "rolitetracycline" [All Fields] OR "tetracycline" [All Fields] OR "tigecycline" [All Fields]) AND ("tooth replantation" [MeSH Terms] OR "tooth replantation" [All Fields]). The reference lists of the relevant studies were also searched to identify any additional relevant articles.

\section{Study inclusion and exclusion criteria}

Inclusion criteria were as follows:

1. Types of studies. Studies that estimated the efficacy of tetracyclines on pulp revascularization and periodontal healing after tooth replantation were included. For human studies, both randomized and non-randomized clinical trials were included. For animal studies, the experimental group should undergo the same procedure as the control group, while the additional application of tetracyclines was given in the intervention group. 
2. Types of subjects. Subjects included in this review should be animals or human beings. For the former, experimenters should be approved by the appropriate Ethics Committee for Animal Experiments. For the latter, the human subjects signed an informed consent before the research procedures.

3. Types of interventions. Interventions should be application of tetracyclines to the avulsed teeth. Compounded trials, in which replanted teeth in the experimental group were subjected to some other medications besides tetracyclines or some chemical compounds including other ingredients, were excluded.

Exclusion criteria were as follows:

Reviews, case reports, cohort studies, retrospective studies, descriptive studies, letters, opinion articles, and abstracts were excluded.

\section{Study inclusion}

Two reviewers (MM and $\mathrm{YC}$ ) independently conducted the search, screening the titles and abstracts. The full texts were further evaluated for studies appearing to meet the inclusion criteria or when information given by the abstracts was insufficient to judge whether the articles met the inclusion criteria or not. This procedure was also conducted independently and in duplicate by two review authors (MM and YC). A third person (JZ) from our team provided input as needed.

\section{Assessment of risk of bias}

Risk of bias assessment was undertaken according to Cochrane Handbook for Systematic Reviews of Interventions. The features of interest in the standard "Risk of bias" table of Cochrane review were as follows: random sequence generation (selection bias), allocation sequence concealment (selection bias), blinding of participants and personnel (performance bias), blinding of outcome assessment (detection bias), incomplete outcome data (attrition bias), selective outcome (reporting bias), and other potential sources of bias. Each entry of these features addressed a specific feature of the included studies. They were judged as "low risk", "high risk", or "unclear risk", with the last category indicating either lack of information or uncertainty over the potential for bias. Two independent reviewers ( $\mathrm{MM}$ and $\mathrm{YC}$ ) conducted the assessment of risk of bias in duplicate. Disagreement was resolved by discussing with a third reviewer (JZ).

\section{Data extraction}

Basic information of the included studies were extracted and recorded independently and in duplicate by two reviewers using a data extraction form, including participants details, teeth replanted, stage of root development, the status of root canal during the experiment (endodontically treated or not), extra-alveolar time, storage conditions, splinting or not, application of tetracyclines, duration of study, observation methods, observation content, interventions for each group and the final conclusions.

\section{Results}

\section{Search results}

The primary search resulted in 246 articles. 227 studies did not meet the inclusion criteria and were excluded after reading of titles and abstracts. Four papers were excluded after evaluation of the full texts [30, 31, 37, 49]. There were 15 articles brought into this systematic review after applying the exclusion and inclusion criteria. The procedures of electronic searching are presented in Fig. 1.

\section{Characteristics of included studies}

All articles that met our inclusion criteria were animal studies. There were ten studies evaluating the effect of topical application of tetracyclines on pulp and periodontal healing [21, 24, 27-29, 34-36, 50, 51]. Five studies focused on the influence of systemic tetracyclines after tooth replantation [23, 25, 26, 32, 33]. The duration of these studies ranged from 7 days to 6 months. Most teeth were kept dry. And teeth were kept wet intraorally in saliva in two papers $[23,24]$. The extra-alveolar time ranged from less than 5-60 min. More information about the characteristics of the included studies is illustrated in Table 1.

\section{Methodological and quality assessment}

Randomization was performed in three studies [23, 28, 29]. Blinding of outcome assessment was carried out in two studies [21, 34]. Five articles received a moderate risk of bias [21, 23, 28, 29, 34]. Ten articles showed a high risk of bias [24-27, 32, 33, 35, 36, 50, 51]. Risk of bias assessment according to the Cochrane Handbook for Systematic Reviews of Interventions for each study is presented in Table 2.

\section{Effect of tetracyclines on pulpal and periodontal healing}

The basic procedure conducted in the control group was similar with the experimental group. Only the additional application of tetracyclines was given in the intervention group. And the specific operation for the intervention and control group in different studies was summarized in Table 3. The administration and dosage of tetracyclines, methods used to evaluate the effect of tetracyclines on pupal and periodontal healing, and the outcomes of each study was also shown in Table 3. 


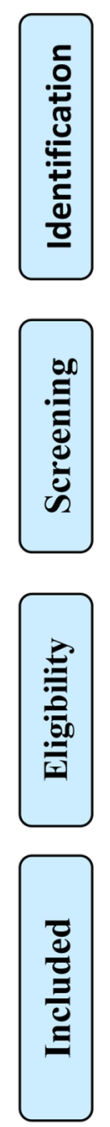

Search of electronic database \& website: PubMed (50), Medline (44), Embase (15), Web of Science (84), CENTRAL (2), and PRL (51): 246 in total $(\mathrm{n}=246)$

Records screened by title and abstract reading after duplicates removed $(\mathrm{n}=154)$

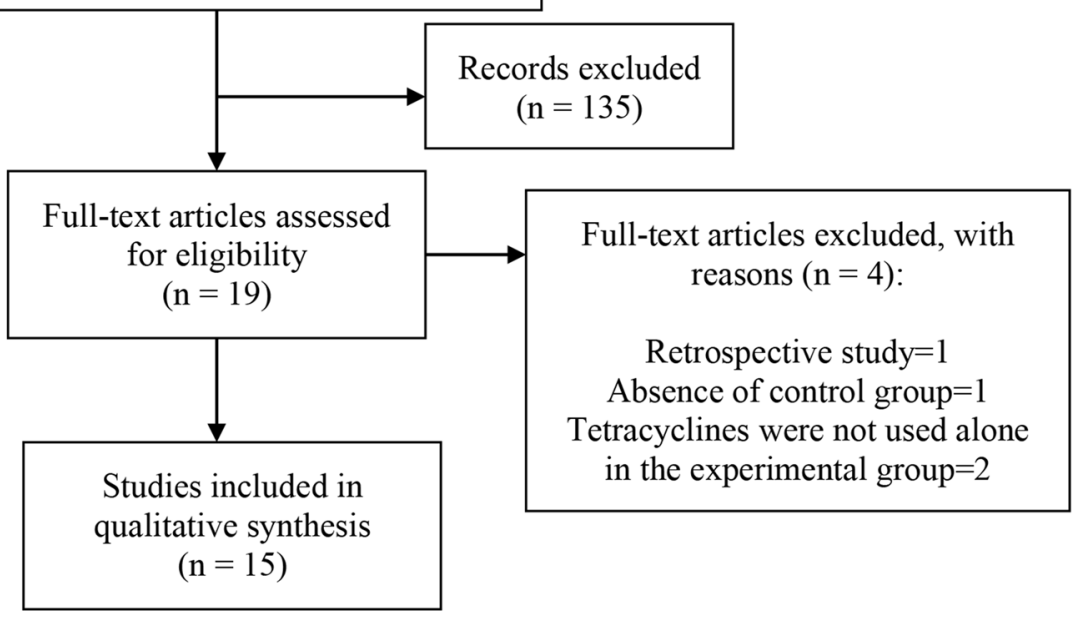

Fig. 1 Systematic search and selection strategy (flow chart)

\section{Pulpal healing}

Five articles evaluated the effect of tetracyclines on pulp revascularization in replanted teeth $[23,24,28,29,50]$.

\section{Topical application}

Yanpiset [29] and Cvek [24] revealed that topical application of doxycycline increased the frequency of complete pulp revascularization, while Ritter [28] showed the number of vital teeth in doxycycline-treated specimens was higher than saline-treated specimens, but no statistical significance was observed. Ritter [28] also illustrated that minocycline-treated specimens presented a significantly more number of vital tooth than saline-treated specimens. Liu [50] found avulsed permanent teeth treated with doxycycline did not show a better clinical outcome for pulp survival.

\section{Systemic application}

Cvek [23] illustrated that intravenous administration of doxycycline exerted no effect on the occurrence of complete pulp revascularization in reimplanted teeth.

\section{Periodontal healing}

Twelve papers reported the effect of tetracyclines on periodontal healing in replanted teeth.

\section{Topical application}

The frequencies of ankylosis and inflammatory root resorption was statistically decreased in immature teeth soaked in doxycycline solution [24]. Replanted mature teeth filled with demeclocycline in the root canals showed significantly more favorable healing than the roots filled with Gutta-Percha [21]. The inhibitory effect of topical application of minocycline and tetracycline on root resorption was not significantly different from the control group [27, 34-36]. Nam [51] found that doxycycline improved the periodontal healing of replanted teeth stored for 60 min in HBSS, whereas doxycycline did not improve periodontal healing of replanted tooth after 5 min of dry storage. Only one human study showed that periodontal healing was similar between the teeth treated with normal saline and the one treated with doxycycline [50]. 


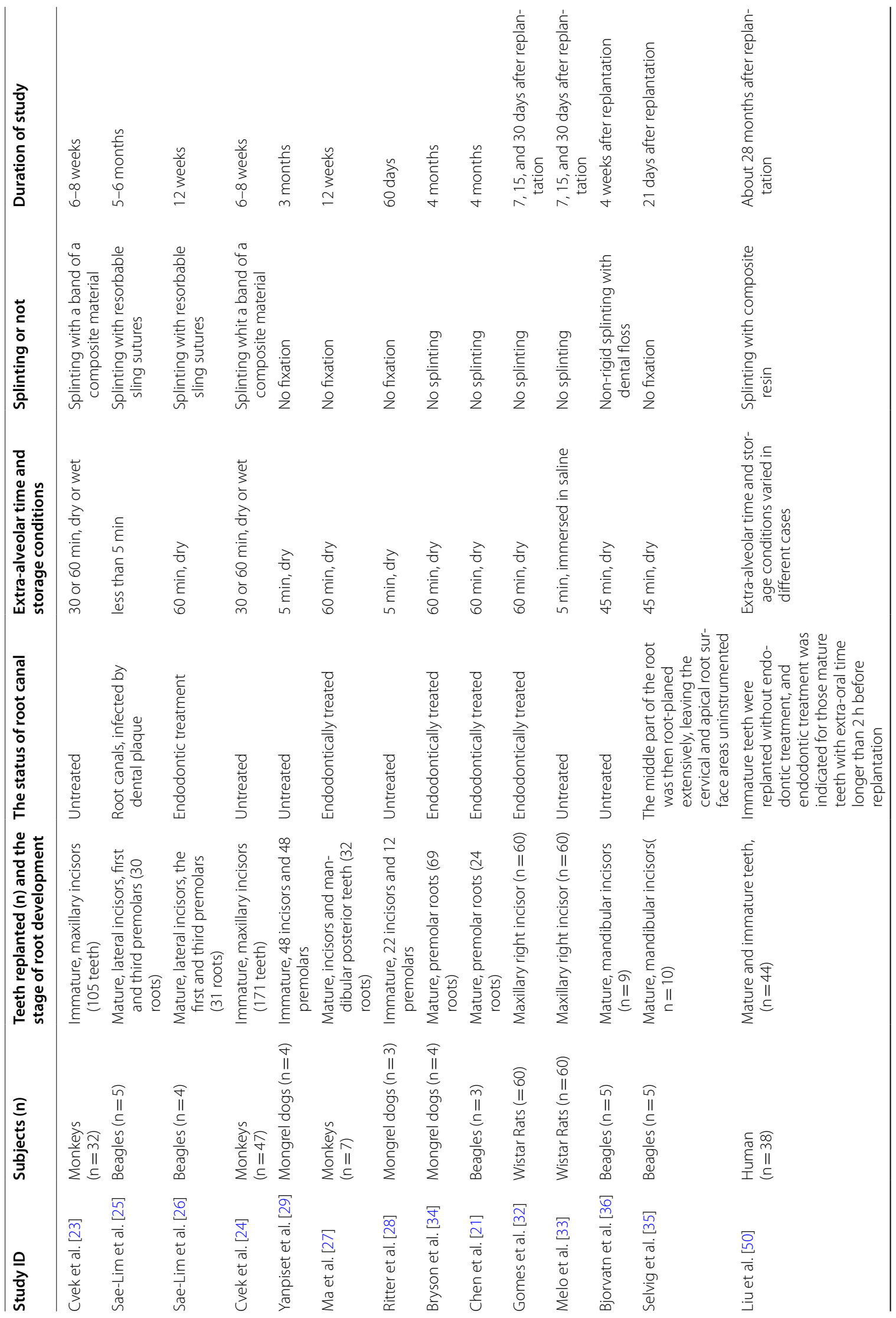




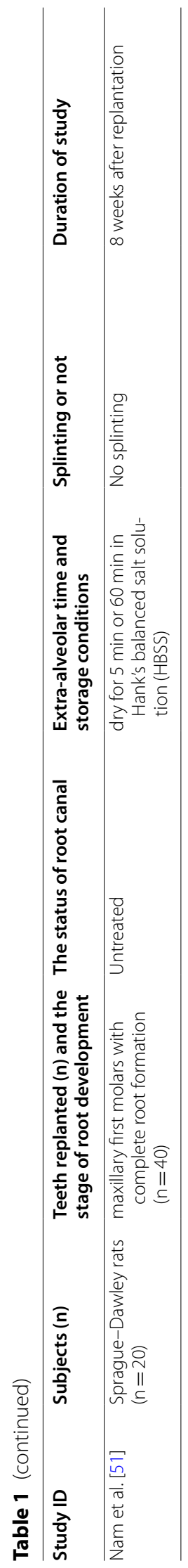


Table 2 Quality assessment of the included studies

\begin{tabular}{|c|c|c|c|c|c|c|c|}
\hline Studies & $\begin{array}{l}\text { Random } \\
\text { sequence } \\
\text { generation }\end{array}$ & $\begin{array}{l}\text { Allocation } \\
\text { concealment }\end{array}$ & $\begin{array}{l}\text { Blinding of } \\
\text { participants and } \\
\text { personnel }\end{array}$ & $\begin{array}{l}\text { Blinding of } \\
\text { outcome } \\
\text { assessment }\end{array}$ & $\begin{array}{l}\text { Incomplete } \\
\text { outcome data }\end{array}$ & $\begin{array}{l}\text { Selective } \\
\text { reporting }\end{array}$ & Other bias \\
\hline Cvek et al. [23] & + & $?$ & + & - & + & + & + \\
\hline Sae-Lim et al. [25] & - & $?$ & + & - & + & + & + \\
\hline Sae-Lim et al. [26] & - & $?$ & + & - & + & + & + \\
\hline Cvek et al. [24] & _- & $?$ & + & - & + & + & + \\
\hline Yanpiset et al. [29] & + & $?$ & + & - & + & + & + \\
\hline Ma et al. [27] & - & $?$ & + & - & + & + & + \\
\hline Ritter et al. [28] & + & $?$ & + & - & + & + & + \\
\hline Bryson et al. [34] & - & $?$ & + & + & + & + & + \\
\hline Chen et al. [21] & - & $?$ & + & + & + & + & + \\
\hline Gomes et al. [32] & - & $?$ & + & - & + & + & + \\
\hline Melo et al. [33] & - & $?$ & + & - & + & + & + \\
\hline Bjorvatn et al. [36] & - & $?$ & + & - & + & + & + \\
\hline Selvig et al. [35] & - & $?$ & + & - & + & + & + \\
\hline Liu et al. [50] & - & - & - & - & + & + & + \\
\hline Nam et al. [51] & _ & $?$ & + & _ & + & + & + \\
\hline
\end{tabular}

,+ low risk of bias;, high risk of bias; ?, unclear risk of bias

\section{Systemic application}

The inflammatory reaction was less intense and the complete healing was more common in the tetracycline group administered by oral gavage compared with control group, but the difference was also not statistically significant, no matter in the mature teeth [26] or in the rat incisors, with a wide apical foramen simulating the open apex of immature teeth [32,33]. Mature teeth with dental plaque filled in the root canals showed significantly more complete healing and less inflammatory root resorption after oral administration of tetracycline than the control group [25].

\section{Discussion}

Pulpal and periodontal healing are two main concerns of delayed replantation of avulsed teeth, and immediate replantation is recommended for the purpose of getting the success of pulp revascularization and periodontal ligament healing $[4,5]$.

\section{Root resorption and bacterial invasion}

In avulsed teeth, mechanical trauma causing periodontal damage, might initiate the root resorption. This process could lead to removal of cementoblasts, precementum and sometimes cementum in areas of the root surface. Pulp necrosis, secondary to the displacement of teeth, makes necrotic pulp tissue much more vulnerable to microorganisms, which can reach the root canal through enamel-dentin cracks and exposed dentinal tubules. Bacteria and their irritants from the infected root canal could penetrate to the root surface through the dentinal tubule [52]. Damaged predentin and precementum might maintain and aggregate resorptive process [53]. Bacterial contamination left on the root surface and socket might also result in root resorption.

\section{Possible mechanisms of tetracyclines}

The process of tooth resorption is considered to be similar to that of bone resorption. It is caused by osteoclasts, which are large and multinucleated cells, differentiated from hematopoietic mesenchymal stem cells along monocyte and macrophage lineage [54]. Antibiotics are recommended after tooth replantation in most situations and tetracyclines are the first choice [55]. Rifkin et al. [56] tried to illustrate the mechanism behind these activities and found that tetracyclines might inhibit bone resorption by decreasing osteoclast ruffled border, diminishing acid production and secreted cysteine proteinases, inducing cell retraction, elevating intracellular calcium, scavenging reactive oxygen species and possible inhibition of osteoclast collagenase. At the same time, they could exert influence on osteoblasts by increasing alkaline phosphatase and collagen synthesis to promote bone formation. Tetracyclines can also promote fibroblast and connective tissue attachment, enhancing regeneration of periodontal attachment [48].

The effect of tetracyclines is related to the concentration applied. In comparatively low concentration, known as subantimicrobial dose, they can inhibit the activity of matrix metalloproteinases and collagenase, and their 


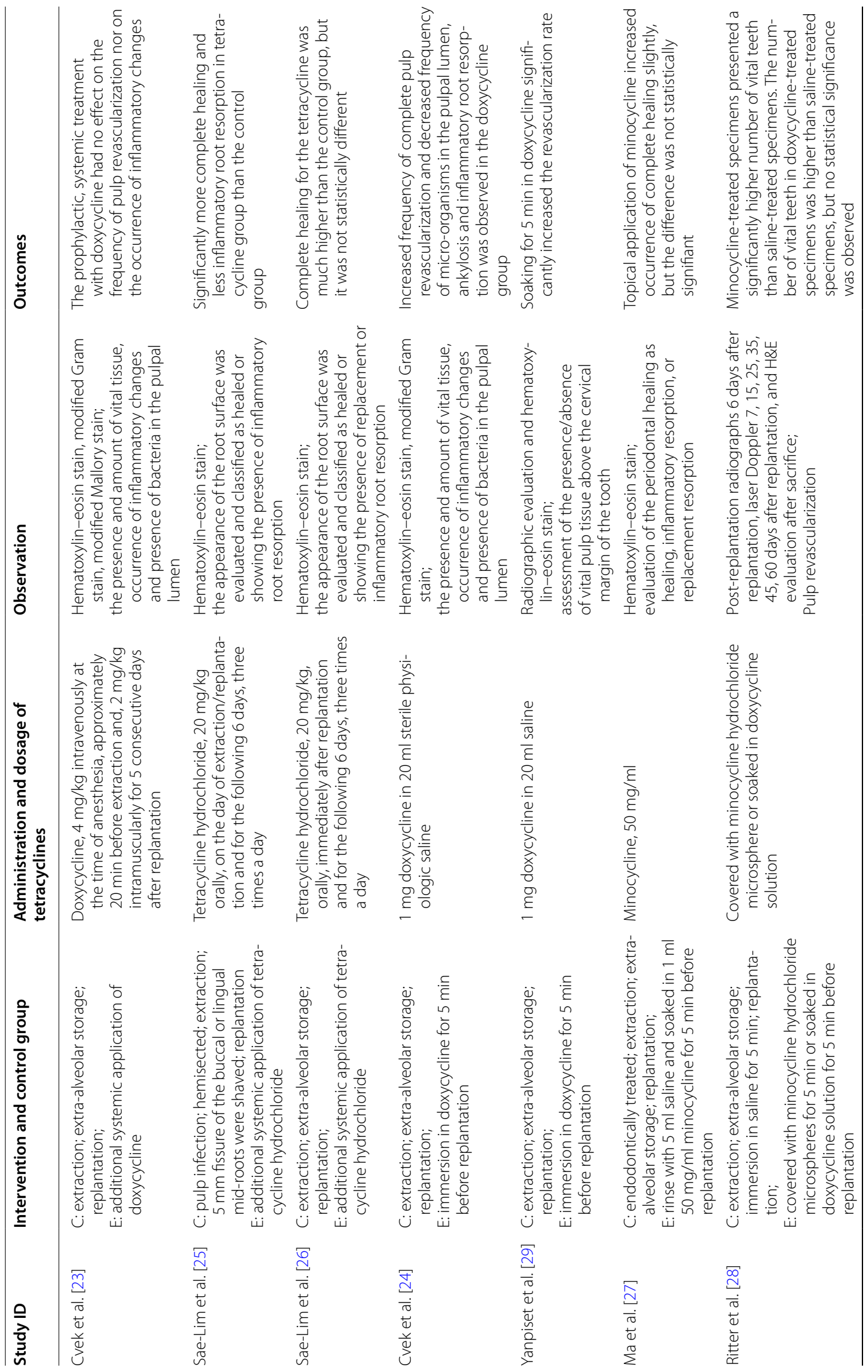




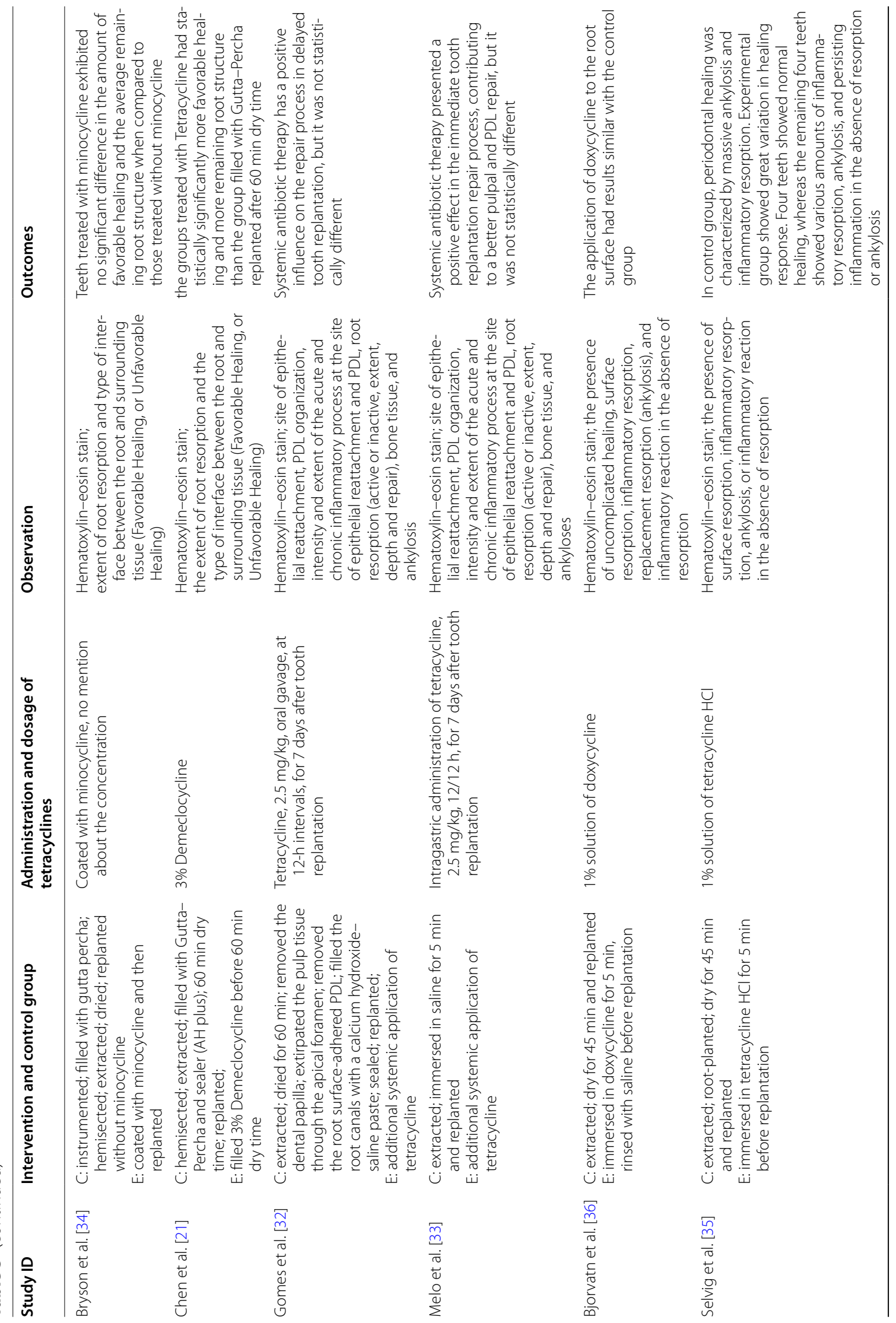




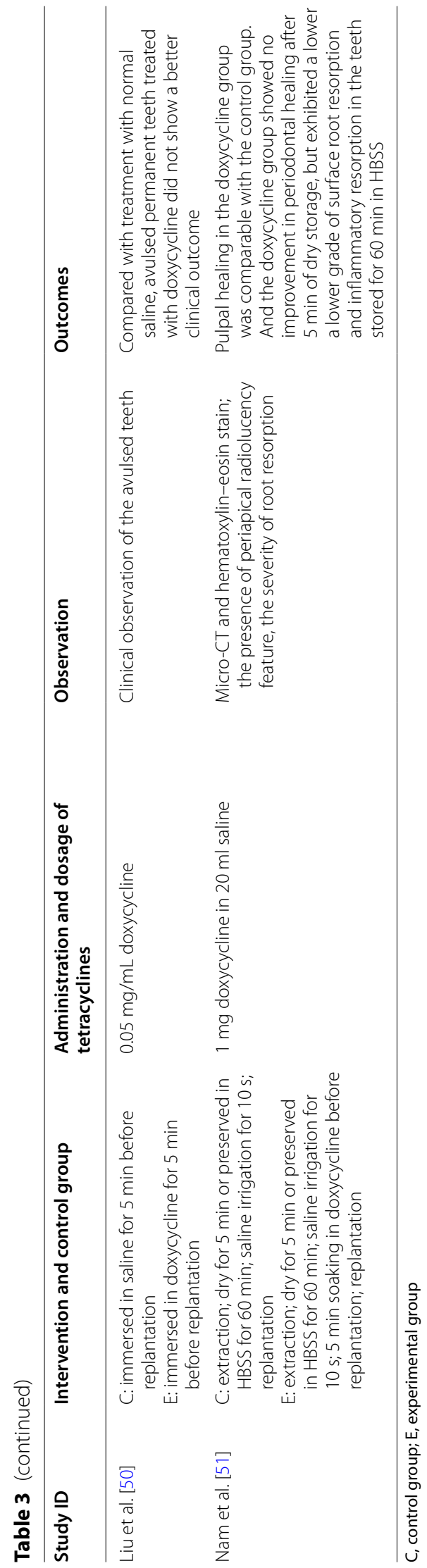


degradation of non-osseous and osseous connective tissues [57]. Non-antibacterial tetracycline formulations have been used in periodontitis, dermatologic diseases, arthritis, cardiovascular disease [58-61]. In normal therapeutic concentrations, they have antibacterial activity by inhibiting bacterial protein synthesis and provide action against anaerobes, facultatives, rickettsia, mycoplasmas, chlamydia, and against a wide range of Gram-positive and Gram-negative organisms. However, a local application of high concentrations may cause tissue damage [62].

Tetracycline and its derivatives can strongly adsorb to tooth surfaces and then be slowly released in active forms, a property which prolongs therapeutic effectiveness [63]. In the research conducted by Cvek, pulp revascularization was significantly higher in group with the topical application of doxycycline than the control group [24]. This might be related to the antibacterial effect of doxycycline. Modified Gram stain was used to detect possible existence of micro-organisms in the pulpal lumen and dentinal tubules in this study. The results yielded that the frequency of micro-organisms was lower in the experimental group than control group. When the teeth with micro-organisms were excluded from the comparison, no difference of pulp revascularization was found between groups. This outcome indicated that the lower prevalence of bacterial in the pulpal lumen was responsible for the higher frequency of revascularization in the experimental group of teeth. Another result strengthened this point further. That is, fewer microorganisms were found in the group of immediately reimplanted teeth compared to the species with 30- and 60-min extra-alveolar time intervals, and a higher frequency of complete revascularization was demonstrated for the group of teeth reimplanted immediately $[23,24]$. Another study showed that pulp revascularization occurred in $73 \%$ and $33 \%$ of the specimens in doxycycline-treated group and control group, separately. But the difference was not statistically significant. The small sample size might be responsible for this result. Whether there exist other reasons for this inconsistent outcome needs further study.

\section{Application of tetracyclines in tooth replantation}

Cvek et al. reported that the topical application of doxycycline on tooth surface would facilitate the periodontal healing [24]. This might be related to the high frequency of complete pulp revascularization of these immature teeth ascribed to the use of doxycycline in the experimental group. Bacteria and their irritants from the infected root canal of necrotic pulp might participate in the resorptive process and hinder periodontal healing [52].

In the included studies of systemic application of tetracyclines, the dosages were $2 \mathrm{mg} / \mathrm{kg}$ in monkeys [23],
$2.5 \mathrm{mg} / \mathrm{kg}$ in rats $[32,33]$ and $20 \mathrm{mg} / \mathrm{kg}$ in dogs $[25,26]$. According to the equivalent dose translation between human and animal studies based on the body surface area (BSA) normalization method [64], the dosage for rats was subantimicrobial, while these for monkeys and dogs were antimicrobial. Four studies showed that systemic administration of tetracyclines could exert favorable effect on pulpal and periodontal healing in individuals, but the difference was not statistically significant between groups, no matter subantimicrobial or antimicrobial doses were used [18, 21, 27, 28]. And the results between mature and immature teeth were similar. The most common routes of infection after tooth replantation are the gingival tissues, periodontal tissues, main root canal, lateral canals, and dentinal tubules. Cvek et al. [23] demonstrated that the micro-organisms after tooth replantation were mainly seen in contaminated blood clots, located in the apical portion of the pulpal lumen or between abscesses below the vital tissue and the necrotized pulp. These bloods were formed during the injury and pushed into the pulpal lumen during the reimplantation. The amount of antibiotics diffusing into the replanted teeth after systemic administration is low, so it is difficult to play a role in inhibiting the growth and spread of the bacteria. Meanwhile, the variable absorption efficiency by oral gavage in different cases might contribute to the highly inconsistent results. However, A study carried out by Sae-Lim [25] showed that systemic tetracycline given orally could result in more complete periodontal healing and less inflammatory root resorption than blank control group. Root canals were filled with dental plaque and roots were shaved in this study, making it difficulty in comparing with others.

Filling the extracted roots with 3\% Demeclocycline has been reported to be effective in facilitating more favorable healing and more remaining root structure than roots filled with Gutta-Percha [21]. But, possible side effect of this kind of root canal medicaments should be taken seriously since there is evidence suggesting that Ledermix (a paste containing triamcinolone and demeclocycline) might cause a darkening and gray-brown discoloration, which is unacceptable to patients $[65,66]$. This adverse reaction is common during long-term use of the drugs [67]. Tsilingaridis et al. [30] applied doxycycline topically on avulsed permanent teeth in children, and there were no records pointing out that storing the avulsed teeth in a suspension of $1 \mathrm{mg}$ doxycycline solution for $5 \mathrm{~min}$ will cause tooth discoloration. Systemic application of tetracyclines is often within one week, which is too short to produce any discoloration of the developing teeth [68]. Meanwhile, tooth replantation is advisable, since we should give priority to facial growth and development over esthetics [69]. 


\section{IADT guidelines}

The International Association of Dental Traumatology (IADT) recommended systemic administration of antibiotics after avulsion and replantation to prevent infection-related reactions and to decrease the occurrence of inflammatory root resorption even though the value of systemic administration of antibiotic is highly questionable. Besides amoxicillin and penicillin, tetracycline and doxycycline are alternative antibiotics recommended after avulsion and replantation. And a specific topical antibiotic, duration of use, or methods of application is not recommended [55].

The effect of amoxicillin on healing of periodontal tissue was inconsistent compared to the treatment of tetracycline. Gomes [32] and Melo ME [33] found the effect of systemic amoxicillin on periodontal ligament repair was better than tetracycline, while studies conducted by Sae-Lim V [25, 26] illustrated the opposite result. The dosages of tetracycline used were $2.5 \mathrm{mg} /$ $\mathrm{kg}$ in the former two studies and $20 \mathrm{mg} / \mathrm{kg}$ in the latter two studies, while the dosages of amoxicillin were $25 \mathrm{mg} / \mathrm{kg}$ and $22 \mathrm{mg} / \mathrm{kg}$, respectively. This difference of applied dosages could affect the topical concentration of medicaments and the effect of antibiotics further, leading to contrary results.

The foremost limitation in this review is that only one human study was available [50]. Meanwhile, the administration, category, dosage of tetracyclines vary in different studies, which might reduce the comparability. This shortcoming confines the guidance of this systematic review. Hence, more studies are required to further estimate the effect of tetracyclines on pulpal and periodontal healing after tooth replantation.

\section{Conclusions}

As a result of data heterogeneity and limitations of the studies, the effect of topical or systemic application of tetracyclines on pulpal and periodontal healing is inconclusive. More studies are required to get more clinically significant conclusions.

\section{Abbreviation}

PRISMA: Preferred Reporting Items for Systematic Reviews and Meta-Analyses.

\section{Acknowledgements \\ Not applicable.}

\section{Authors' contributions}

MM and YC conducted the data search, extraction, assessment and the statistical analysis and drafted the manuscript. HR and QZ made the figures and tables. SC organized the structure of the manuscript and edited the language. XZ and JZ designed the study and revised the manuscript. All authors read and approved the final version of submission.

\section{Funding}

International cooperation in science and technology innovation/Cooperation Program in Science and Technology Innovation of Hong Kong, Macao and Taiwan, Science \& Technology Department of Sichuan Province (No. 2019YFH0025) supported the design of the study and collection, analysis, and interpretation of data and writing and publishing the manuscript.

\section{Availability of data and materials}

The summary of data extraction in this study is available upon request to the corresponding author.

\section{Declarations}

Ethics approval and consent to participate

Not applicable.

Consent to publish

Not applicable.

\section{Competing interests}

The authors declare that they have no competing interests.

\section{Author details}

${ }^{1}$ State Key Laboratory of Oral Diseases and National Clinical Research Center for Oral Diseases, West China Hospital of Stomatology, Sichuan University, Sichuan, China. ${ }^{2}$ Departments of Pediatric Dentistry and Orthodontics, West China Hospital of Stomatology, Sichuan University, Sichuan, China. ${ }^{3}$ Department of Endodontics, West China Hospital of Stomatology, Sichuan University, Sichuan, China.

Received: 8 April 2019 Accepted: 9 May 2021

Published online: 05 June 2021

\section{References}

1. Hecova $H$, Tzigkounakis V, Merglova $V$, et al. A retrospective study of 889 injured permanent teeth. Dent Traumatol. 2010;26(6):466-75.

2. Andreasen JO, Borum MK, Jacobsen $\mathrm{HL}$, et al. Replantation of 400 avulsed permanent incisors. 1. Diagnosis of healing complications. Endod Dent Traumatol. 1995;11(2):51-8.

3. Souza BDM, Dutra KL, Kuntze MM, et al. Incidence of root resorption after the replantation of avulsed teeth: a meta-analysis. J Endod. 2018;44(8):1216-27.

4. Andreasen JO, Borum MK, Jacobsen HL, et al. Replantation of 400 avulsed permanent incisors. 4. Factors related to periodontal ligament healing. Endod Dent Traumatol. 1995;1 1(2):76-89.

5. Andreasen JO, Borum MK, Jacobsen $\mathrm{HL}$, et al. Replantation of 400 avulsed permanent incisors. 2. Factors related to pulpal healing. Endod Dent Traumatol. 1995;11(2):59-68.

6. Andreasen JO, Borum MK, Andreasen FM. Replantation of 400 avulsed permanent incisors. 3. Factors related to root growth. Endod Dent Traumatol. 1995;11(2):69-75.

7. Roskamp L, Westphalen VP, Lima JH, et al. The influence of atopy in the prognosis of the replantation of avulsed teeth. J Periodontol. 2009;80(7):1121-4.

8. Roskamp L, Westphalen VD, Carneiro E, et al. Relationship between extra-alveolar time and atopy in the prognosis of the replantation of avulsed teeth. J Trauma. 2010;69(6):79-81.

9. Sinpreechanon P, Boonzong U, Sricholpech M. Comparative evaluation of periodontal ligament fibroblasts stored in different types of milk: effects on viability and biosynthesis of collagen. Eur J Oral Sci. 2019;127(4):323-32.

10. Osmanovic A, Halilovic S, Kurtovic-Kozaric A, et al. Evaluation of periodontal ligament cell viability in different storage media based on human PDL cell culture experiments: a systematic review. Dent Traumatol. 2018;34(6):384-93. 
11. Wang G, Wang C, Qin M. A retrospective study of survival of 196 replanted permanent teeth in children. Dent Traumatol. 2019;35(4-5):251-8.

12. Petrovic B, Markovic D, Peric T, et al. Factors related to treatment and outcomes of avulsed teeth. Dent Traumatol. 2010;26(1):52-9.

13. Loo WT, Dou YD, Chou WK, et al. Thymosin alpha 1 provides shortterm and long-term benefits in the reimplantation of avulsed teeth: a double-blind randomized control pilot study. Am J Emerg Med. 2008;26(5):574-7.

14. Caglar E, Tanboga I, Süsal S. Treatment of avulsed teeth with Emdogain: a case report. Dent Traumatol. 2005;21(1):51-3.

15. Barbizam JV, Massarwa R, da Silva LA, et al. Histopathological evaluation of the effects of variable extraoral dry times and enamel matrix proteins (enamel matrix derivatives) application on replanted dogs' teeth. Dent Traumatol. 2015;31(1):29-34.

16. Tuna EB, Arai K, Tekkesin MS, et al. Effect of fibroblast growth factor and enamel matrix derivative treatment on root resorption after delayed replantation. Dent Traumatol. 2015;31(1):49-56.

17. Najeeb S, Siddiqui F, Khurshid Z, et al. Effect of bisphosphonates on root resorption after tooth replantation: a systematic review. Dent Traumatol. 2017;33(2):77-83.

18. Kum KY, Kwon OT, Spängberg LS, et al. Effect of dexamethasone on root resorption after delayed replantation of rat tooth. J Endod. 2003;29(12):810-3.

19. Coccia CT. A clinical investigation of root resorption rates in reimplanted young permanent incisors: a five-year study. J Endod. 1980;6(1):413-20.

20. Quispe-Salcedo A, Ida-Yonemochi H, Ohshima H. Effects of a triple antibiotic solution on pulpal dynamics after intentionally delayed tooth replantation in mice. J Endod. 2014;40(10):1566-72.

21. Chen $\mathrm{H}$, Teixeira FB, Ritter AL, et al. The effect of intracanal anti-inflammatory medicaments on external root resorption of replanted dog teeth after extended extra-oral dry time. Dent Traumatol. 2008;24(1):74-8.

22. Kwon Y, Ko H, Kim S, et al. The effect of cathepsin K inhibitor surface treatment on delayed tooth replantation in dogs. Dent Traumatol. 2018;34(3):201-7.

23. Cvek M, Cleaton-Jones $P$, Austin J, et al. Pulp revascularization in reimplanted immature monkey incisors-predictability and the effect of antibiotic systemic prophylaxis. Endod Dent Traumatol. 1990;6(4):157-69.

24. Cvek M, Cleaton-Jones P, Austin J, et al. Effect of topical application of doxycycline on pulp revascularization and periodontal healing in reimplanted monkey incisors. Endod Dent Traumatol. 1990;6(4):170-6.

25. Sae-Lim V, Wang CY, Trope M. Effect of systemic tetracycline and amoxicillin on inflammatory root resorption of replanted dogs' teeth. Endod Dent Traumatol. 1998;14(5):216-20.

26. Sae-Lim V, Wang CY, Choi GW, et al. The effect of systemic tetracycline on resorption of dried replanted dogs' teeth. Endod Dent Traumatol. 1998;14(3):127-32.

27. Ma KM, Sae-Lim V. The effect of topical minocycline on replacement resorption of replanted monkeys' teeth. Dent Traumatol. 2003;19(2):96-102.

28. Ritter ALS, Ritter AV, Murrah V, et al. Pulp revascularization of replanted immature dog teeth after treatment with minocycline and doxycycline assessed by laser Doppler flowmetry, radiography, and histology. Dent Traumatol. 2004:20(2):75-84.

29. Yanpiset $K$, Trope M. Pulp revascularization of replanted immature dog teeth after different treatment methods. Endod Dent Traumatol. 2000;16(5):211-7.

30. Tsilingaridis G, Malmgren B, Skutberg C, et al. The effect of topical treatment with doxycycline compared to saline on 66 avulsed permanent teeth-a retrospective case-control study. Dent Traumatol. 2015;31(3):171-6.

31. Bryson EC, Levin L, Banchs F, et al. Effect of immediate intracanal placement of Ledermix Paste(R) on healing of replanted dog teeth after extended dry times. Dent Traumatol. 2002;18(6):316-21.

32. Gomes WD, Silva CA, Melo ME, et al. Delayed tooth replantation in rats: effect of systemic antibiotic therapy with amoxicillin and tetracycline. Dent Traumatol. 2015;31(6):448-56.

33. Melo ME, Silva CA, de Souza Gomes WD, et al. Immediate tooth replantation in rats: effect of systemic antibiotic therapy with amoxicillin and tetracycline. Clin Oral Investig. 2016;20(3):523-32.
34. Bryson EC, Levin L, Banchs F, et al. Effect of minocycline on healing of replanted dog teeth after extended dry times. Dent Traumatol. 2003;19(2):90-5.

35. Selvig KA, Bjorvatn K, Claffey N. Effect of stannous fluoride and tetracycline on repair after delayed replantation of root-planed teeth in dogs. Acta Odontol Scand. 1990;48(2):107-12.

36. Bjorvatn $\mathrm{K}$, Selvig KA, Klinge B. Effect of tetracycline and SnF2 on root resorption in replanted incisors in dogs. Scand J Dent Res. 1989:97(6):477-82.

37. Selvig KA, Bjorvatn K, Bogle GC, et al. Effect of stannous fluoride and tetracycline on periodontal repair after delayed tooth replantation in dogs. Scand J Dent Res. 1992;100(4):200-3.

38. Pârvu AE, Alb SF, Crăciun A, et al. Efficacy of subantimicrobial-dose doxycycline against nitrosative stress in chronic periodontitis. Acta Pharmacol Sin. 2012;34(2):247-54.

39. Otobe IF, de Sousa SO, Matthews RW, et al. White sponge naevus: improvement with tetracycline mouth rinse: report of four cases. Clin Exp Dermatol. 2007;32(6):749-51.

40. Geisler TM. Clinical considerations for regenerative endodontic procedures. Dent Clin N Am. 2012;56(3):603-26.

41. Park JB. Treatment of peri-implantitis with deproteinised bovine bone and tetracycline: a case report. Gerodontology. 2012;29(2):145-9.

42. Skulason S, Holbrook WP, Thormar $\mathrm{H}$, et al. A study of the clinical activity of a gel combining monocaprin and doxycycline: a novel treatment for herpes labialis. J Oral Pathol Med. 2012;41(1):61-7.

43. Kennedy R, Alibhai M, Shakib K. Tetracycline: a cure all? Br J Oral Maxillofac Surg. 2014:52(4):382-3.

44. Golub LM, McNamara TF, D'Angelo G, et al. A non-antibacterial chemically-modified tetracycline inhibits mammalian collagenase activity. J Dent Res. 1987;66(8):1310-4.

45. Golub LM, Ramamurthy N, McNamara TF, et al. Tetracyclines inhibit tissue collagenase activity. A new mechanism in the treatment of periodontal disease. J Periodontal Res. 1984;19(6):651-5.

46. Keller DC, Carano A. Tetracycline effect on osteoclastic and osteoblastic activity. Gen Dent. 1995;43(1):60-3.

47. Zaidi $\mathrm{M}$, Moonga $\mathrm{BS}$, Huang $\mathrm{CL}$, et al. The effect of tetracyclines on quantitative measures of osteoclast morphology. Biosci Rep. 1993:13(3):175-82.

48. Terranova VP, Franzetti LC, Hic S, et al. A biochemical approach to periodontal regeneration: tetracycline treatment of dentin promotes fibroblast adhesion and growth. J Periodontal Res. 1986;21(4):330-7.

49. Chappuis $V$, von Arx T. Replantation of 45 avulsed permanent teeth: a 1-year follow-up study. Dent Traumatol. 2005;21(5):289-96.

50. Liu Y, Zhu Z, Sun CW, et al. Effects of topical application of doxycycline on avulsed permanent teeth. Shanghai Kou Qiang Yi Xue. 2019;28(6):640-3.

51. Nam OH, Cheon K, Kim MS, et al. Evaluation of the periodontal and pulpal healing of replanted rat molars with doxycycline root conditioning. J Periodontal Implant Sci. 2019;49(3):148-57.

52. Andreasen JO. The effect of pulp extirpation or root canal treatment on periodontal healing after replantation of permanent incisors in monkeys. J Endod. 1981;7(6):245-52.

53. Tronstad L. Root resorption-etiology, terminology and clinical manifestations. Endod Dent Traumatol. 1988:4(6):241-52.

54. Gunraj MN. Dental root resorption. Oral Surg Oral Med Oral Pathol Oral Radiol Endod. 1999:88(6):647-53.

55. Fouad AF, Abbott PV, Tsilingaridis G, et al. International Association of Dental Traumatology guidelines for the management of traumatic dental injuries: 2. Avulsion of permanent teeth. Dent Traumatol. 2020;36(4):331-42.

56. Rifkin BR, Vernillo AT, Golub LM. Blocking periodontal disease progression by inhibiting tissue-destructive enzymes: a potential therapeutic role for tetracyclines and their chemically-modified analogs. J Periodontol. 1993;64(Suppl 8):819-27.

57. GuY, Walker C, Ryan ME, et al. Non-antibacterial tetracycline formulations: clinical applications in dentistry and medicine. J Oral Microbiol. 2012:4:1-14.

58. Caton J, Ryan ME. Clinical studies on the management of periodontal diseases utilizing subantimicrobial dose doxycycline (SDD). Pharmacol Res. 2011;63(2):114-20.

59. Greenwald RA. The road forward: the scientific basis for tetracycline treatment of arthritic disorders. Pharmacol Res. 2011;64(6):610-3. 
60. Monk E, Shalita A, Siegel DM. Clinical applications of non-antimicrobial tetracyclines in dermatology. Pharmacol Res. 2011;63(2):130-45.

61. Meier CR, Derby LE, Jick SS, et al. Antibiotics and risk of subsequent firsttime acute myocardial infarction. JAMA. 1999;281(5):427-31.

62. Bokey L, Hugh TB. Oesophageal ulceration associated with doxycycline therapy. Med J Aust. 1975;1 (8):236-7.

63. Baker PJ, Evans RT, Coburn RA, et al. Tetracycline and its derivatives strongly bind to and are released from the tooth surface in active form. J Periodontol. 1983;54(10):580-5.

64. Kim SG, Kim MH, Chae CH, et al. Downregulation of matrix metalloproteinases in hyperplastic dental follicles results in abnormal tooth eruption. BMB Rep. 2008;41(4):322-7.

65. Day PF, Duggal MS, High AS, et al. Discoloration of teeth after avulsion and replantation: results from a multicenter randomized controlled trial. J Endod. 2011;37(8):1052-7.
66. Chen BK, George R, Walsh LJ. Root discolouration following short-term application of steroid medicaments containing clindamycin, doxycycline or demeclocycline. Aust Endod J. 2012;38(3):124-8.

67. Bierman CW, Cann HM, Cohen SN, et al. Requiem for tetracyclines. Pediatrics. 1975;55(1):142-3.

68. Peterson CD, Abbott PD. Tetracycline's effects on teeth preclude use in children and pregnant or lactating women. Postgrad Med. 1984;76(7):24-34.

69. Andreasen JO, Andreasen FM. Textbook and color atlas of traumatic injuries to the teeth. 3rd ed. Copenhagen: Munksgaard; 1994.

\section{Publisher's Note}

Springer Nature remains neutral with regard to jurisdictional claims in published maps and institutional affiliations.
Ready to submit your research? Choose BMC and benefit from:

- fast, convenient online submission

- thorough peer review by experienced researchers in your field

- rapid publication on acceptance

- support for research data, including large and complex data types

- gold Open Access which fosters wider collaboration and increased citations

- maximum visibility for your research: over $100 \mathrm{M}$ website views per year

At BMC, research is always in progress.

Learn more biomedcentral.com/submissions 